\title{
DESVIACION Y CONTROL EN LAS SOCIEDADES AVANZADAS
}

\author{
Juli Sabaté \\ (Universitat de Barcelona)
}

Siempre hay algún fantasma recorriendo Europa y es muy posible que el que corresponde a nuestros días sea el del aumento de la delincuencia (y el miedo que ello conlleva).

La delincuencia es una parte - políticamente significativa- de un fenómeno social más amplio y complejo, la desviación social. Ésta es definida normalmente como conducta que viola normas y expectativas de cualquier sistema social o modo de dominación y ante la cual éste reacciona con un dispositivo de control específico. Se trata, pues, de un fenómeno de ida y vuelta: la desviación comporta el control y éste - por supuesto- necesita de aquélla. Conviene no perder de vista que normas y expectativas han sido definidas (previamente a que aparezca la desviación, por supuesto) en función de una adecuada protección de las zonas más sensibles para el ejercicio de la dominación, con lo cual la existencia de la desviación puede serle de gran utilidad.

$\mathrm{La}$ inicial afirmación de que la delincuencia es uno de los fantasmas/ realidades más característicos de las llamadas sociedades avanzadas, y el párrafo que le ha seguido, obligan a una primera precisión —que forma parte de lo que podría ser la tesis de este artículo-: no toda la desviación social es el fantasma de nuestra época, lo son tan sólo la delincuencia y su miedo. En efecto, si se considera que las normas y las expectativas contra las que se dirige la desviación social son respectivamente las leyes -básicamente el código penal-y los valores - básicamente los normalizadores-, se puede reconocer sensatamente que estamos ante un proceso de disociación: 
las normas siguen formalmente vigentes (a pesar de, o gracias a, sucesivas reformas del código penal) mientras las expectativas aparecen hoy como más diluidas (la llamada «crisis de valores»); por lo tanto, mientras resultan francamente aparatosos el aumento de la delincuencia y la reacción frente a él, parecen menos evidentes los aumentos de las otras formas no penales de desviación - se discute hasta su propia existencia- y sobre todo ya no producen ni reacción ni miedo comparables.

Vivir diferentemente la propia sexualidad, ganarse la vida alquilando una hermosa parte del cuerpo, pasar de todo, tener unos reflejos mentales y conductuales diferentes, en fin... ser más sensible a la dureza del combate cotidiano y resentirse de él, son formas de vida que la Sociología tradicional había agrupado bajo la etiqueta de desviación social, al mismo nivel que la delincuencia -en sus múltiples formas-, porque no respondían a un modelo de comportamientos homogéneos propio del hombre productivo y a su correspondiente fijación valorativa. Pero las «sociedades avanzadas» han llevado el racionalismo secular al punto que hoy conocemos (y que ya había intuido con un cierto pesimismo Weber), caracterizable, por lo que al tema de este artículo se refiere, a partir de un modelo de comportamientos heterogéneos propio del hombre que produce y consume (libertad-anonimato, igualdad-masa, fraternidad-tolerancia), y a una menor fijación valorativa, con lo cual la desviación en sus formas no penales va quedando más diluida - a diferentes ritmos según sus diferentes formas.

El proceso de racionalización parece, pues, haber llegado también al terreno de la desviación y su control. Las zonas más sensibles (la vida, la propiedad, la intimidad) están claramente señaladas - penalmente señaladas-, mientras que para el resto de conductas que se apartan de la normalidad existe un doble dispositivo: por un lado, sutil presión hacia la conformidad y el consenso, y por otro lado tolerancia y aceptación social a niveles variables según la intensidad de la desviación, su cercanía a las zonas sensibles y el medio en el que se produzca. Parafraseando el viejo slogan político de nuestro país, se trata de reservar la unidad y el rigor para lo esencial, siendo más flexible en lo accidental (es mucho más rentable).

$\mathrm{Y}$ vayamos ya a la delincuencia, es decir, al conjunto de comportamientos desviados que afectan a las zonas más sensibles del sistema y que consecuentemente están definidos por el código de justicia penal. La tesis del presente artículo se centrará, pues, en la delincuencia, al señalar que las transformaciones de las sociedades avanzadas no son ajenas a dos datos no por manidos menos ciertos:

1. El aumento y la diversificación de la delincuencia.

2. El aumento del miedo y de las demandas de control. 


\section{EL AUMENTO Y LA DIVERSIFICACION DE LA DELINCUENCIA}

Es un lugar común el reconocer que la delincuencia en las sociedades. avanzadas es un fenómeno que crece sin cesar, tanto cuantitativamente, por el aumento de su volumen, como cualitativamente, por la multiplicidad de formas con las que se presenta. La pretensión de cuantificar ambos procesos es dificultosa por evidentes razones de investigación, pero sobre todo es sesgada porque normalmente sólo cuenta un tipo de delincuencia, la Ilamada «convencional», que es la más funcional al ejercicio del control; por lo tanto, limitaré los datos a lo imprescindible para poder apreciar el aumento de volumen - referido, por supuesto, a la delincuencia convencional- y hacer una breve reflexión sobre la diversificación formal, para, a continuación, señalar aquellas características de las sociedades avanzadas que puedan considerarse como factores delictógenos.

\subsection{El aumento}

La delincuencia ha ido aumentado en toda Europa de forma sostenida durante los últimos veinte años (por ejemplo, en Francia aumentó en un $322,2 \%$ en el período que va de 1963 a 1982 - Bonnemaison 1982; 12). En España, el despegue del crecimiento de la delincuencia se produce coincidiendo con la década de los años setenta, aunque por obvias razones nadie se entere hasta 1975; para el primer quinquenio de nuestra década, los datos policiales hablan de un salto desde los 327.414 delitos conocidos en 1980 hasta los 687.440 de 1984: en cinco años casi se ha doblado la cifra (D. G. de la Policía, 1986; 39). Por lo que hace referencia a la ciudad de Barcelona, en una serie temporal más breve, los delitos conocidos por la policía pasaron de 21.757 en el primer semestre de 1983 a 32.829 en el primer semestre de 1984 (CTSU, 1985; 63); asimismo, las encuestas de la Comisión Técnica de Seguridad Urbana del Ayuntamiento de Barcelona (CTSU) señalan un aumento de 11,6 puntos entre 1983 y 1984 y un nuevo aumento de 14 puntos entre 1984 y 1985 .

\subsection{La diversificación}

$Y$ en cuanto a las nuevas formas de la delincuencia, posiblemente el hecho más espectacular que se puede reseñar sea la definitiva extensión, también a este terreno, del proceso de corporatización: sigue existiendo, por 
supuesto, el delincuente solitario (ifaltaría más!), pero la organización se impone, y frente a ésta, aquél está perdido. El proceso de corporatización se da en la delincuencia tradicional o convencional (ahí está, por ejemplo, el progresivo aumento de la delincuencia en banda), pero sobre todo se da en la delincuencia no convencional (aumento o aparición de delincuencia de cuello blanco, del delito organizado -obsérvese el adjetivo-, de la delincuencia informática, etc., etc.).

Viene a cuento recordar aquí con Salvador Giner que «vamos a un tipo esencialmente diferente de sociedad en el que la realidad social general es negociada corporativamente entre las diversas coaliciones, y en la que los perdedores máximos son aquellos marginados sociales de débil o nula representación corporativa...» (Rizzi, 1982; 29): el delincuente solitario es hoy el perdedor máximo, tanto si opera en el marco de la delincuencia convencional como si se atreve a irrumpir en el peligroso mundo de la delincuencia no convencional.

\subsection{Sociedades avanzadas y delincuencia}

El impacto de los cambios sociales en los cambios del panorama delictivo puede analizarse fundamentalmente desde dos puntos de vista: el psicosocial y el meramente factorial.

El primero es el que sigue, por ejemplo, Jean Pinatel cuando señala que la organización de las sociedades modernas facilita el desarrollo de los cuatro rasgos de la personalidad delictiva: la labilidad, el egocentrismo, la agresividad y la indiferencia afectiva (Pinatel 1979; 70-90).

El segundo, en el que me detendré con una cierta extensión porque es el que conecta con el nervio de este artículo, repasa la estructura social viendo los aspectos de la misma que pueden actuar como factores delictógenos; resulta claro que la Sociología criminal está en este punto lejos de la pretensión de hacer un análisis causal. El análisis que sigue pretende ser un catálogo - revisable, por supuesto- que presente y estimule la reflexión y la discusión sobre aquellos aspectos estructurales que pueden ser considerados total o parcialmente factores delictógenos; hay que precisar también que la incidencia de dichos aspectos puede ser desigual en intensidad y extensión, puede también variar temporal y geográficamente, y que indistintamente trataré de la delincuencia convencional y de la no convencional.

1. Aspectos de la estructura demográfica que pueden ser factores delictógenos. 
La baja sostenida de las tasas de mortalidad y el incremento de la esperanza de vida suelen ser considerados como indicadores de desarrollo socio-económico; pero, simultáneamente, están en la base de la aparición y la reivindicación de los «grupos de edad». Desde esta segunda perspectiva, la reivindicación de los grupos adolescente y juvenil puede devenir un factor de incremento de delincuencia no utilitaria (propia de bandas adolescentes) e incluso de delincuencia utilitaria en momentos de crisis económica.

Por otra parte, no hay que olvidar que los movimientos de población, cuando son estructurales, numéricamente importantes, y se producen en el contexto de una integración problemática (económica, racial, idiomáticocultural, etc.), pueden convertirse también en factor delictógeno. En el caso de España, la trascendencia de este posible factor puede calibrarse recordando con García Barbancho que «nunca, en la historia de España, ha habido en tan corto espacio de tiempo - los últimos treinta años- un trasiego humano tan considerable (...). De ahí que a las migraciones de nuestro tiempo, en particular a las interiores, las califiquemos como el fenómeno demográfico más relevante habido en España» (G. Barbancho, 1982; 92-93).

2. Hablar en nuestro país de la estructura económica como factor delictógeno es hoy moneda corriente a causa del paro; en efecto, todo el mundo - políticos, periodistas y encuestas de opinión - coincide en que el paro tiene mucho que ver con el aumento de la delincuencia. Si se considera esta problemática con detenimiento, es posible reconocer que el hecho de tener más del $20 \%$ de la P. A. en paro puede tener los siguientes efectos sobre la delincuencia: un posible aumento directo de la misma -el parado que roba para comer o que agrede por exasperación-, aunque la cuantificación de este hecho es de considerable dificultad y también de dudosa utilidad, en los estudios de la CTSU se estimó que la delincuencia producto directo del paro podría ser establecida en alrededor de un $30 \%$ del total; en segundo lugar, hay un posible aumento de la delincuencia por vía indirecta (el impacto del paro en la actividad delictiva de allegados y familiares), de cuantificación y medida aún más problemáticas. A continuación habría que hablar de la economía subterránea - directamente relacionada con el paro- y señalar su posible incidencia en un aumento de la delincuencia por los innegables aspectos delictivos que presenta (tráfico de drogas, contratos ilegales, etc.); y en cuarto lugar (last but not least), cabe contar con un previsible aumento de la franja marginal de la población, un descenso de la credibilidad de las instituciones afectadas - fundamentalmente las políticas - no menos previsible, y correlativamente un aumento de la inseguridad y el miedo.

No se puede concluir el repaso al problema del paro sin ofrecer un

10. 
par de reflexiones derivadas de él y que afectan no tanto quizás a la delincuencia como a la marginalidad: en primer lugar, es preciso recordar las dificultades de acceso de la población juvenil al mercado de trabajo por el menor índice de renovación del mismo y por la destrucción de empleo (del paro juvenil como factor delictógeno se ha hablado tanto que no vale la pena insistir aquí); y en segundo lugar, conviene no perder de vista que la salida tecnológicamente avanzada de la crisis - por la que parecen optar decididamente nuestras autoridades políticas-- puede hacer crecer la «masa marginal» de la población (la fuerza de trabajo difícilmente reubicable o reciclable por edad, recursos, formación, etc., etc.).

De todas formas, el paro no agota (ni mucho menos) las posibilidades de impacto de la economía moderna en el aumento de la delincuencia. Así, en líneas generales se puede pensar que un modelo económico basado en la libre competencia y la supervivencia del más fuerte es un constante factor de delincuencia utilitaria (asimilable a la desviación innovadora de que habla la teoría de la anomia mertoniana -Merton, 1964; 150), tanto por abajo, la delincuencia convencional, como por arriba, la delincuencia de cuello blanco (para este segundo supuesto, es útil el dicho de la criminología crítica de que más allá de los mil millones todas las fortunas se han hecho robando).

Por otra parte, en criminología se suele admitir que «cuando el nivel de vida aumenta por el desarrollo de la actividad económica, aumenta paralelamente la delincuencia adquisitiva porque dicho desarrollo, al incrementar las relaciones económicas, estimula la aparición de ocasiones suplementarias de delincuencia por la multiplicación de relaciones de interés que conlleva necesariamente» (Pinatel, 1975; 156); de donde se puede suponer, con toda lógica, que la economía de las sociedades avanzadas puede generar una delincuencia específica (delincuencia financiera, inmobiliaria, espionaje industrial e informático, etc., etc.).

3. Por lo que a la política se refiere, habría que hacer dos observaciones. Una primera, universalista, en la que hay que señalar que, si la delincuencia es un fenómeno político (el poder legislativo define el delito, el judicial define al delincuente, y el ejecutivo es mediador entre ambos y filtro entre ellos y la realidad), la crisis de legitimidad del Estado y la cuestión de la ingobernabilidad - fenómenos ambos propios de las sociedades avanzadas - pueden considerarse como factores delictógenos en la medida en que dejan en suspenso y/o exigen una remodelación de las definiciones acabadas de señalar y de la mediación y el filtraje que lleva a cabo la acción de gobierno del poder ejecutivo. Una segunda, concretada al caso español y a la llamada «transición política» de nuestro país, en la que se impone anali- 
zar los cambios de esta década desde el punto de vista de su posible contribución al aumento de la delincuencia: la transición se ha ido haciendo con desiguales ritmos en las distintas instituciones de nuestro sistema político (parlamento, judicatura, policía, etc.) con el previsible desajuste entre sus actuaciones y la no menos previsible dificultad de coordinación de sus intervenciones; súmese a esto el también desigual efecto de los cambios en el interior de cada institución y en los profesionales que trabajan en ellas (modificación de los objetivos políticos y profesionales, resistencias y/o arrogancias, crisis de identidad y posteriores reformulaciones profesionales y también políticas, etc., etc.). Todo ello -fundamentalmente las dificultades de coordinación y el cambio institucional - ha generado fisuras notables en el dispositivo político del control de la delincuencia que, como es bien sabido, han sido bien aprovechadas no sólo por los delincuentes, sino también por las diferentes oposiciones políticas que se han ido turnando en el Parlamento: el resultado ha sido una cierta espiral (a más fisuras más delincuencia y más críticas, y así sucesivamente) y sobre todo la entronización en nuestro panorama político del discurso sobre la inseguridad y la necesidad del control.

Justo es reconocer, no obstante, que nuestra transición política ha ocasionado la disminución - la casi total eliminación, podríamos decirde un tipo de delincuencia específico del régimen político anterior: la llamada delincuencia política (los delitos de orden público y de opinión). La actualidad política internacional puede ser considerada también como factor delictógeno en otros temas de capital importancia social, pero que escapan de los límites del presente artículo: violaciones de los derechos humanos, agresiones imperialistas, terrorismo, etc.

Finalmente, hay que colocar en esta lista de factores delictógenos la política penal y penitenciaria (no hay que olvidar que se ha definido la cárcel como la «universidad del delito»).

4. De la estructura cultural y sus instituciones habría que destacar los siguientes aspectos «modernos» como posibles factores delictógenos:

a) La cultura moderna es asociativa y no comunitaria. La Sociología lleva ya años señalando como causantes de la desazón de nuestro tiempo la disolución de los lazos comunitarios y su ausencia de recambios, y el carácter utilitario y cínico de los lazos asociativos que hoy predominan en las relaciones sociales.

Todo ello puede ser considerado un factor delictógeno genérico, especificable en distintos aspectos: 
- La crisis de los agentes tradicionales de control social de tipo comunitario.

- El correspondiente anonimato masivo, que, oportunamente articulado con el utilitarismo y el cinismo, contribuye a la formación de la personalidad delincuente antes señalada por Pinatel.

- También podemos inscribir aquí la problemática subcultural (de larguísima tradición sociológica y de sangrante actualidad en los últimos años) derivada de la progresiva heterogeneidad que acompaña a la cultura moderna.

b) Es preciso hacer una referencia específica a un cambio ideológico que se está produciendo en nuestra cultura: estamos dirigiéndonos a lo que se podría definir como «la ideología de la seguridad», caracterizable por la exageración que hoy presenta en amplios segmentos de la población la, en principio, natural y lógica búsqueda de seguridad (en el trabajo, en la circulación, en la calle, en la salud, etc.): se está yendo a buscar una seguridad total y omnímoda cueste lo que cueste (en contra de las más elementales lecciones de la vida, porque, como decía Raimon, «ja el ndixer és un gran plor»); esto, en el terreno que nos ocupa, implica un alto grado de intolerancia y actitudes punitivas respecto a la delincuencia. (Sería interesante rastrear los orígenes mesocráticos de tal ideología, con lo cual su carácter político quedaría en evidencia como factor de conformidad - la respetabilidad, etc.).

c) La transformación del modelo familiar que hemos conocido en las últimas dos décadas (la llamada "crisis de la familia», el vacío doméstico, la falta de alguna figura $\rightarrow$ de las dos- adulta, la pérdida de funciones de la familia, etc.) genera utilitarismo, cinismo, aumento de la problemática juvenil, despreocupación socializadora, etc. Por otra parte, periódicamente aparecen en la prensa familias en crisis como indicadores patéticos de la «crisis de la familia» (niños maltratados o abandonados, etc.).

d) En el caso de la institución escolar, se impone hablar del «fracaso escolar» como posible factor delictógeno - seguramente con efectos menores de lo que se suele afirmar-; pero también hay que mencionar el «fracaso de la escuela» (su incapacidad para acercarse a la realidad subcultural de gran parte de la población infantil en medio marginal, y por tanto la ausencia de sentido que tiene para estos niños). Ambos fenómenos son propios de las sociedades modernas. 
e) El proceso de secularización puede también ser considerado desde una perspectiva criminológica como factor delictógeno porque debilita, o hasta elimina, un poderoso agente de control social sin ofrecer un recambio laico.

f) Los mass-media y la organización del tiempo libre: ambos fenómenos son distintivos de las sociedades avanzadas, y su orientación crematístico-especulativa (sensacionalismo en los primeros y práctica ausencia de actividades creativas en la segunda) puede entrar en este catálogo; ofrecen con frecuencia modelos de ideales para identificación y comportamiento como mínimo dudosos.

g) La red de grupos primarios va configurándose, desde hace también bastante tiempo, como el sistema no institucional más importante de vehiculación de cultura. Dicha red es importante en la adolescencia (las bandas), frecuentemente no es vehículo de cultura sino de subcultura, y a veces el consumo y hasta el tráfico de drogas penetra por ahí.

5. No se puede cerrar este catálogo de posibles factores delictógenos derivados de las características de las sociedades avanzadas sin hacer una referencia a la vida urbana: no sólo se trata de relacionar la delincuencia con las áreas urbanas (en la tradición de la ecología de Chicago), sino de constatar que, si bien la vida moderna es urbana y el tipo de delincuencia propia de la ciudad es astuto y sofisticado, las disfunciones del urbanismo que se ha practicado en nuestro país han comportado, en sus ciudades, tanto la delincuencia específicamente urbana como la propia de las zonas rurales.

Se ha resuelto hasta aquí el primero de los dos datos antes introducidos: «las transformaciones de las sociedades avanzadas no son ajenas al aumento y la sofisticación de la delincuencia». A continuación, y para comprobar que tampoco son ajenas al aumento del miedo y de las demandas de control, reseñaré brevemente resultados del programa de investigación de la CTSU referidos a la ciudad de Barcelona, que puede ser considerada como un exponente de los problemas de las sociedades avanzadas.

\section{EL AUMENTO DEL MIEDO Y DE LAS DEMANDAS DE CONTROL}

El informe final de la CTSU empezaba con las siguientes palabras: «El fenómeno colectivo del miedo a la delincuencia ha adquirido en nuestras 
sociedades una importancia política capital. Periódicamente, la población se siente amenazada en su instinto de seguridad y exige que el Estado ejerza uno de sus monopolios más importantes e incontestados: el derecho a castigar. Simultáneamente, esta preocupación por la seguridad ciudadana se sitúa entre las preocupaciones principales de la opinión pública» (CTSU 85 , a; 30). Los miedos colectivos han sido una constante a través de la Historia (miedo a catástrofes naturales, a guerras, epidemias, etc.), pero es genuino de nuestra época el miedo a la delincuencia, tal como se presenta con una estructura propia de un fenómeno social de considerable envergadura económica (la llamada industria de la seguridad), política (el discurso al respecto es hoy piedra de toque político y forma parte de toda campaña electoral que se precie), ideológica (la anteriormente citada ideología de la seguridad en lo que se refiere a la delincuencia), etc., etc.

Miedo y demanda de control son las dos caras complementarias de esta misma moneda (a más miedo, más demanda de control, y a más demanda de control, más miedo). $\mathrm{Y}$ a esto se le llama en nuestras sociedades modernas «inseguridad ciudadana» o «inseguridad urbana». La inseguridad hunde sus raíces en la realidad (el innegable aumento de la delincuencia, por ejemplo) y en el sentimiento (una auténtica construcción mitológica de la inseguridad): ambas raíces son simultáneamente complementarias ( «la sensibilidad social contribuye a la definición y a la medida del fenómeno; sólo se establecen estadísticas para aquello que preocupa»-Coing y Meunier, 1980; 11) y antinómicas (la realidad puede ir por un lado y los sentimientos por otro como luego se verá).

\subsection{Miedo a la delincuencia e inseguridad}

En principio, la inseguridad tendría que ser algo más que el estricto miedo a la delincuencia (Dulong, 1985; 146) y así nos lo planteamos en los inicios de los trabajos de la CTSU; definíamos allá la SC * como «el resultado de una negociación constante entre la búsqueda de seguridad en la convivencia y la realidad insegura de la vida del hombre en la Tierra, negociación que ha de ofrecer un marco social seguro para que cada individuo pueda afrontar libremente la inseguridad de su vida» (CTSU, 1985 a, 52 ss.). Esta negociación - proseguíamos- exige unas condiciones de normalidad en la estructura social que cuando no se dan (por ejemplo, el paro, etc.) producen inseguridad, y ésta se manifiesta en seis aspectos de la vida social; los seis aspectos eran los siguientes:

* SC: Seguridad Ciudadana. 
a) La delincuencia en aumento (en cifras absolutas y relativas) y con ella el aumento de la violencia en la sociedad.

b) Una mayor visibilidad social, y sobre todo una mayor problematización de la marginación social entendida doblemente como:

- Por un lado lo que podríamos llamar «marginación pasiva» (vagabundos, mendigos, etc.), que ha comportado el aumento de la picaresca, fenómeno éste muy propio de nuestro país.

- Por otro lado, las fugas hacia la marginalidad de sectores de la población cada vez más importantes, especialmente de la franja juvenil.

c) La calidad de vida deteriorada - y cada vez más estropeada. En este terreno, los principales aspectos que habría que considerar serían la polución, las molestias y el descontrol industriales y problemas concretos como por ejemplo la adulteración de los productos alimenticios.

d) La progresiva pérdida de lo que podríamos llamar «solidaridad urbana», el civismo y la colaboración en la convivencia en la calle.

e) El terrorismo, que ha superado el ámbito político y el marco geográfico iniciales.

f) Indefensión ante imprevistos catastróficos: la experiencia de los últimos años demuestra hasta la saciedad que, a pesar del innegable progreso técnico que ha experimentado nuestro país en los últimos años, la población sigue insegura frente a imprevistos (accidentes, incendios, inundaciones, etc.) que no encuentran ningún sistema serio de defensa (CTSU, 1985 a; 57-58).

Pero tanto los trabajos con grupos como las encuestas demostraron que nos equivocábamos: la gente no entiende más inseguridad ciudadana que la que se deriva del miedo a la delincuencia, es decir, del miedo a perder la integridad f́́sica o los bienes personales..., juntamente, eso sí, con el miedo al paro - porque pone en cuestión la integridad de los bienesy el miedo a los drogadictos - porque se ha dicho y repetido que el $80 \%$ de los delitos se cometen bajo los efectos de la droga. Así, para ilustrarlo con un ejemplo, en todas las encuestas de la CTSU aparece como miedo más poderoso el producido por la delincuencia, seguido por el del paro y el de los drogadictos, tal como se ve en la siguiente tabla: 
Miedo a

Octubre 84 Octubre 85

- Ser víctima de un acto terrorista

8,5

5,6

- Que le afecte un incendio o un accidente en locales públicos

- La contaminación del ambiente en la ciudad ...

- Los drogadictos

- La posibilidad de ser víctima de un accidente de circulación

2,4

7,3

13,2

13,2

12,9

$2,8 \quad 4,4$

26,8

24,3

26,0

23,6

7,3

$1,1 \quad 1,3$

- Que le vendan alimentos en mal estado

- La asistencia médica en hospitales y ambulatorios

- Que le engañen o le estafen en sus compras ...

2,4

1,3

0,3

4,1

1,8

- La presencia de mendigos en las calles

0,4

$-\mathrm{N} / \mathrm{S}, \mathrm{N} / \mathrm{C}$

Delincuencia, paro y drogadictos preocupan -y por este orden- a prácticamente las dos terceras partes de la población.

\subsection{La inseguridad: datos elementales}

Una vez identificado el miedo a la delincuencia con la inseguridad, procede ofrecer algunos datos que permitan describir la situación actual para poder acabar analizando las líneas maestras de lo que es hoy la construcción de la inseguridad.

Para esta descripción utilizaré sistemáticamente material de encuesta proveniente de los trabajos de la CTSU del Ayuntamiento de Barcelona; dicho material, que tiene todas las ventajas y todos los inconvenientes de las encuestas, es el más útil para el objetivo de estas líneas, que es ofrecer una mera descripción, una lectura bastante objetiva, de la situación actual de la inseguridad concretada en la ciudad de Barcelona. Las tablas con los resultados utilizados van agrupadas al final del artículo para no interrumpir el hilo de la lectura: corresponden todas a la encuesta de 1985.

1. La gente se siente insegura (en las diferentes encuestas de la CTSU siempre aparece una franja superior al $60 \%$ de la población que confiesa experimentar mucho o bastante la sensación personal de inseguridad).

2. Esta sensación, que había aumentado de forma aparatosa en los 
últimos años, parece estabilizarse (según los resultados de la primera encuesta, el $64 \%$ de la población opinaba que la situación había empeorado en los últimos años contra sólo un $17 \%$ que opinaba que había mejorado, y en la última encuesta realizada el $34 \%$ de la población cree que hemos mejorado en los últimos meses y el $27 \%$ cree que seguimos empeorando).

3. La inseguridad se refiere, en primerísimo lugar, a los delitos que afectan a la integridad física, y en segundo lugar a los que afectan a la integridad del hogar. Los datos que aparecen en la tabla núm. 1 son explícitos al respecto: el ítem que más temor provoca son las agresiones físicas, que preocupan al $44 \%$ de la población, y sumándoles las violaciones -que figuran en cuarto lugar - la preocupación por la integridad física alcanza al $60 \%$ de los encuestados. Por su parte, el miedo al robo de la vivienda casi llega al $20 \%$.

4. La inseguridad ha llevado a la gente a tomar medidas individuales. No es en absoluto exagerado afirmar que, según los datos de las encuestas, cada individuo ha tomado en consideración un promedio de cuatro medidas (aunque es cierto que muchas de ellas son más aplicaciones de sentido común que medidas frente a la delincuencia). Puede hablarse de medidas «pasivas» (no llevar dinero encima, evitar lugares oscuros, salir menos de noche, etc., etc.) y «activas» (reforzar las puertas, instalación de alarmas, procurarse armamento, etc., etc.); y conviene destacar que las pasivas son prácticamente el doble que las activas, mientras que las medidas específcamente de autodefensa son prácticamente insignificantes. Los datos referidos a esta cuestión aparecen en la tabla núm. 2.

5. Se está de acuerdo en considerar que el paro y la crisis económica contribuyen al aumento de la delincuencia y de la inseguridad, pero también se opina que el incremento del consumo de drogas y el trato excesivamente benevolente con los detenidos - la poca dureza de las penastienen un fuerte impacto en ello.

Puede ser significativo un análisis de esta opinión: cuando se responden las preguntas de una encuesta, normalmente se impone la razón (y, por tanto, se reconoce la responsabilidad del paro y la crisis económica), pero no por ello dejan de aparecer, insostenibles por las respuestas racionales, la punitividad - que ya habíamos encontrado al hablar de la ideología de la seguridad - y el miedo a la droga - que también hemos ido encontrando antes de ahora. Los datos referidos a esta cuestión aparecen en la tabla núm. 3.

6. Las soluciones al problema de la inseguridad son dobles; por un lado, las medidas individuales que toma cada cual; $y$ por otro, las medidas de tipo político que pueda tomar la Administración. Éstas son, de 
acuerdo con lo anterior, solucionar el problema del paro, sancionar con mayor rigor y dureza a los delincuentes y controlar la droga. Como se puede observar en la tabla núm. 4, en la investigación de las soluciones al problema se ha seguido una doble táctica; primero se formula la pregunta de modo abierto para obtener una respuesta espontánea, y a continuación se presenta una tarjeta con una lista de soluciones sugeridas. Pues bien, la «solución» espontáneamente más citada por los encuestados es el «no sabe, no contesta», dato que -aparte de problemas técnicos de redacción del cuestionario- habla de la pasividad con que la población se enfrenta al problema.

\subsection{La construcción de la inseguridad}

No hay que subestimar las dificultades que presenta la pretensión de analizar el fenómeno de la inseguridad, pero tampoco hay que sobreestimarlas (V. Dulong 1983), de manera que voy a ofrecer una posible explicación que tal vez pueda servir de base a ulteriores reflexiones sobre el tema.

En la construcción de la inseguridad intervienen dos componentes de coexistencia, inicialmente interdependiente y posteriormente bastante independiente, que son una innegable base real y una potente creación mitológica. La base real, a su vez, tiene un doble fundamento:

- El aumento de la delincuencia, el aumento del consumo de drogas, el previsible aumento de la masa marginal de la población, las dificultades del dispositivo de control, etc.

- Su misma realidad como «hecho social» en sentido durkheimiano: nos es exterior y se nos impone.

Pero la inseguridad es también mito, porque a partir de esa base real $e$ independizándose progresivamente de ella, aparece a su vez como fruto de una auténtica construcción mitológica de la realidad siguiendo, por tanto, también las leyes del mito, de donde resultan tres consecuencias:

- El mito no es controlable por el hombre; por tanto, el miedo que produce es concreto y real y simultáneamente confuso, difuso y profuso. Hay una constante en la estructura del miedo a la delincuencia, consistente en que es un estado de ánimo que no tiene por qué tener un objeto concreto ni real (los hombres tienen miedo a las violaciones, la gente teme menos el barrio que la ciudad, no se socorre a un accidentado o no se da lumbre a un transeúnte por temor a una trampa, etc., etc.). Los trabajos actuales de investigación de la CTSU van en esta dirección. 
- Hay también una considerable dosis de fatalidad (el mito comporta el «fatum»): no se puede luchar contra él y por tanto su vivencia es «fatal» y genera lógicamente actitudes pasivas. (Dos ejemplos serían las medidas «pasivas» que adopta la gente y la enorme frecuencia de los «no sabe/no contesta» cuando a la gente se le pregunta por las posibles soluciones a la delincuencia.)

- Se sigue también una cierta crispación (fruto del miedo y la fatali$\mathrm{dad} /$ pasividad), y de ella fácilmente surgen las actitudes punitivas. Las actitudes punitivas frente a la delincuencia - llamadas también «bajo índice de tolerancia» a la misma - se ven constantemente por la calle, han aparecido ya cuando se han analizado las razones del aumento de la delincuencia (la poca dureza de las penas) y sus soluciones (castigar más), y pueden también percibirse en los datos que ofrece la tabla núm. 5 .

$\mathrm{El}$ análisis del carácter mítico de la inseguridad puede continuarse con el descubrimiento de un culpable (el malo) que actúa como cabeza de turco -en la más genuina y depurada tradición mitológica-: el incremento del consumo de droga (que por otra parte tiene un sólido componente real); y puede concluirse reconociendo que nunca como hoy un mito había tenido unos vehículos de expresión tan enormes: los medios de comunicación de masas.

Los dos componentes de la inseguridad — realidad y mito- inician su andadura interdependientemente, pero siguen leyes de funcionamiento propias que los independizan hasta extremos como los siguientes:

1. Según los resultados de las encuestas de la CTSU, en la ciudad de Barcelona la delincuencia aumentó entre 1984 y 1985; según las mismas encuestas, la vida en la misma ciudad era sentida más segura en 1985 que en 1984.

2. La tabla de la página siguiente ofrece una correlación entre los delitos que realmente se producen y los que la gente cree que son los más frecuentes, los que más aumentan o los que más miedo dan (resultados también de encuesta).

3. También según los resultados de las encuestas de la CTSU, los distritos municipales de la ciudad de Barcelona de mayor sensación de miedo son precisamente los de menor riesgo, y los espacios concretos vividos como más inseguros tienen en la realidad un índice bajísimo de delitos.

A la vista de todo lo referido, podríamos concluir con Peyrefitte que el significado de la inseguridad es básicamente emocional (poco reflexivo) y oscila entre el miedo y la exasperación conformando un cuadro clínico de 


\begin{tabular}{|c|c|c|c|c|}
\hline \multirow[b]{2}{*}{ Tipo de delito } & \multirow[b]{2}{*}{$\begin{array}{l}\text { Victimiza- } \\
\text { ción real } \\
\text { Base } 100\end{array}$} & \multicolumn{3}{|c|}{ Opinión de la población encuestada } \\
\hline & & $\begin{array}{c}\text { Delitos más } \\
\text { frecuentes } \\
\text { Base } 100\end{array}$ & $\begin{array}{c}\text { Delitos más } \\
\text { aumento } \\
\text { Base } 100\end{array}$ & $\begin{array}{c}\text { Delitos más } \\
\text { miedo } \\
\text { Base } 100\end{array}$ \\
\hline $\begin{array}{l}\text { Robo de objetos en el } \\
\text { interior del coche }\end{array}$ & 29,5 & 6,24 & 8,3 & 0,8 \\
\hline $\begin{array}{l}\text { Robos de coches y motos } \\
\text { (intentos y consumados) }\end{array}$ & 17,8 & 8,97 & 9,8 & 2,2 \\
\hline $\begin{array}{l}\text { Robos en la calle } \\
\text { (tirón e intento) }\end{array}$ & 22,4 & 25,62 & 18,2 & 7,9 \\
\hline Robos en la vivienda & 9,1 & 21,40 & 16,7 & 28,9 \\
\hline Atracos (e intentos) & 11,6 & 13,5 & 18,7 & 20,7 \\
\hline Robos y atracos a comercios & 5,4 & 17,6 & 22,6 & 2,5 \\
\hline Amenazas & 1,6 & 0,4 & 0,5 & 1,1 \\
\hline Violencia física & 1,6 & 2,5 & 2,5 & 23,2 \\
\hline Violación & 0,8 & 3,5 & 2,6 & 12,6 \\
\hline Total & 100 & 100 & 100 & 100 \\
\hline
\end{tabular}

una cierta angustia colectiva. Las manifestaciones más visibles de esta sensación son:

- La inhibición (el retraimiento): no salir de casa, disimular cuando se ve algún problema, etc.

- La constante demanda de actuación de los poderes públicos.

- Las reacciones individuales (en los últimos años ha aumentado la. venta de todo tipo de artilugios de protección — puertas blindadas, alarmas, etcétera-y también han aumentado las academias y los gimnasios en los. que se aprende defensa personal, judo, karate, etc.).

- La creación de sistemas de protección colectiva (empresas de seguridad, piquetes de vecinos, etc.) (Peyrefitte 1977; 52-63).

\subsection{Conclusión: la seguridad ciudadana, un fenómeno politico}

$\mathrm{Ph}$. Robert, en un reciente artículo, señalaba las dificultades que presenta el estudio de la inseguridad y concluía en el fracaso de todas las clasificaciones conceptuales para transformar en objeto científico una noción elaborada en y por la polémica política (Robert, 1985; 199). A la vista de los resultados de los trabajos de la CTSU es imposible no estar de acuerdo 
con esa conclusión: si detrás del aumento de la delincuencia puede haber todo un conglomerado de factores, detrás del miedo y las demandas de control lo que hay fundamentalmente es una gran operación política.

En efecto, la demanda de seguridad ha aparecido en las sociedades avanzadas movilizando mecanismos relativos al «yo» (mi seguridad, mi pasividad, mi intimidad...), a las diversas posesiones del «yo» (mis bienes, mi integridad física...), y exagerando la necesidad de disfrutar de ello con lo que en el lenguaje político se llama «libertad»-y que no es otra cosa que la pretensión de una total seguridad. Para ello, se apela a los poderes públicos; se introducen una quiebra en la solidaridad (yo soy el bueno y el mal me vendrá de los otros) y una ruptura con la más elemental lógica vital (yo quiero estar totalmente seguro); y consecuentemente con todo ello se ponen en juego componentes irracionales de fácil explotación política (el miedo, la respetabilidad, etc.).

El resultado es asegurat el control interior de la población, aislarla (no salir, no confiar, etc.), reforzar las tendencias hacia la conformidad, y sobre todo poner en el mercado de los valores a la Seguridad como valor en alza. (Esto sin contar con los otros efectos «menores» que también pueden ser mencionados; por ejemplo, el refuerzo de los estereotipos, la criminalización de actitudes - la famosa «mala pinta» en el vestir como síntoma de ser sospechoso-, la pérdida de alegría, etc., etc.)

Si no me equivoco, todo esto es un fenómeno político: es conservadurismo - más bien de vía estrecha - que interesa a los poderes de las sociedades avanzadas; es dato ideológico propio de clase media que puede contaminar y contamina a las clases subalternas; es, en definitiva, manifestación de la manipulabilidad que caracteriza a nuestra organización social.

Creo que con estas líneas puede haber quedado claro que un hecho a considerar, cuando se habla de sociedades avanzadas, es que sus transformaciones pueden afectar el aumento y la diversificación de la delincuencia y que la lógica de la dominación que en ellas se da puede acarrear este fantasma moderno que es el miedo a la delincuencia y las demandas de control. 
«Papers»: Revista de Sociologia

TABLA 1

Tipos de delito que provocan más temor en \% (según sexo y edad)

\begin{tabular}{|c|c|c|c|c|c|c|}
\hline \multirow[b]{2}{*}{ Tipo de delito } & \multicolumn{3}{|c|}{ Sexo } & \multicolumn{3}{|c|}{ Edad } \\
\hline & Total & Hombre & Mujer & $18-35$ & $36-55$ & +55 \\
\hline Violencia & 24,9 & 28,5 & 21,8 & 27,0 & 23,9 & 23,7 \\
\hline Atracos calle & 19,7 & 23,6 & 16,4 & 13,4 & 19,8 & 26,0 \\
\hline Robo vivienda & 18,8 & 18,8 & 18,8 & 11,3 & 19,9 & 25,2 \\
\hline Violaciones & 16,0 & 4,3 & 26,1 & 28,3 & 15,7 & 4,1 \\
\hline Secuestros & 5,2 & 6,9 & 3,8 & 7,3 & 5,7 & 2,7 \\
\hline Vandalismo & 3,9 & 5,0 & 3,0 & 3,3 & 3,6 & 4,8 \\
\hline Robo bolso & 3,4 & 1,7 & 4,8 & 1,6 & 3,2 & 5,3 \\
\hline Ningún delito & 1,7 & 2,3 & 1,2 & 0,7 & 1,2 & 3,2 \\
\hline Amenazas & 1,3 & 1,5 & 1,1 & 1,6 & 1,1 & 1,3 \\
\hline Robos coche & 1,2 & 2,0 & 0,5 & 2,0 & 1,2 & 0,5 \\
\hline $\mathrm{N} / \mathrm{S}$ & 1,2 & 1,3 & 1,1 & 1,0 & 1,2 & 1,4 \\
\hline Robos comercios & 1,0 & 1,5 & 0,5 & 0,8 & 1,4 & 0,8 \\
\hline Atracos bancos & 0,9 & 1,3 & 0,5 & 1,4 & 1,5 & 0,6 \\
\hline Robos int. coche & 0,5 & 0,8 & 0,2 & 0,7 & 0,6 & 0,2 \\
\hline Estafas/timo & 0,5 & 0,6 & 0,4 & 0,6 & 0,5 & 0,3 \\
\hline Otros delitos & 0,5 & 0,4 & 0,6 & 0,3 & 0,5 & 0,7 \\
\hline $\mathrm{N} / \mathrm{C}$ & 0,4 & 0,4 & 0,4 & 0,3 & 0,6 & 0,9 \\
\hline
\end{tabular}


Desviación y control en las sociedades avanzadas

TABLA 2

Medidas para proteger la seguridad personal/familiar en $\%$ total y agrupadas en Activas y Pasivas *

\begin{tabular}{|c|c|c|c|c|c|}
\hline \multirow[b]{2}{*}{ Tipos de medidas } & \multirow{2}{*}{$\begin{array}{c}\% \\
\text { Total }\end{array}$} & \multicolumn{2}{|r|}{$\begin{array}{c}\% \\
\text { Total }\end{array}$} & Tipos de medidas & $\begin{array}{c}\% \\
\text { Total }\end{array}$ \\
\hline & & Activas & & \multicolumn{2}{|l|}{ Pasivas } \\
\hline Evitat lugares oscutos & 57,9 & Reforzar puertas & 56,7 & Evitar lugares oscuros & 57,9 \\
\hline No llevar dinero & 56,8 & Seguro contra robo & 28,9 & No llevar dinero & 56,8 \\
\hline Reforzat puertas & 56,7 & Vigilantes & 24,2 & No salir solo & 43,8 \\
\hline No salir solo & 43,8 & Alarma en coche & 12,5 & Salir menos de noche & 39,0 \\
\hline Salit menos de noche & 39,0 & Sistema de alarma & 5,3 & Ocultar dinero & 23,1 \\
\hline Seguro contra robo & 28,9 & Comprar un perro & 5,2 & Hijos pronto a casa & 22,1 \\
\hline Vigilantes & 24,2 & Caja fuerte & 4,1 & Salir menos a la calle & 8,6 \\
\hline Ocultar dinero & 23,1 & Arma en casa & 2,7 & No dejar dinero & 0,4 \\
\hline Hijos pronto a casa & 22,1 & Arma en la calle & 2,2 & No llevar joyas & 0,1 \\
\hline Alarma en coche & 12,5 & Arma en el coche & 1,7 & & \\
\hline Salir menos a la calle & 8,6 & Rejas en ventanas & 0,4 & Total & 251,8 \\
\hline Ninguna & 6,8 & Alarma en comercio & 0,1 & & \\
\hline Sistema de alarma & 5,3 & & & & \\
\hline Comprat un perto & 5,2 & Total & 144 & & \\
\hline Caja fuerte & 4,1 & & & & \\
\hline Arma en casa & 2,7 & & & & \\
\hline Arma en la calle & 2,2 & & & & \\
\hline Arma en el coche & 1,7 & & & & \\
\hline Otras medidas & 0,8 & & & & \\
\hline Rejas en ventanas & 0,4 & & & & \\
\hline No dejar dinero & 0,4 & & & & \\
\hline Alarma en comercio & 0,1 & & de pa & ivas respecto al total - & . 63,62 \\
\hline No llevar joyas & 0,1 & $\%$ & de a & ivas respecto al total & 36,38 \\
\hline
\end{tabular}

* Cada porcentaje representa el \% de medidas que se han tomado en Barcelona. No tiene lectura vertical, ya que una persona adopta varias medidas. 
«Papers»: Revista de Sociologia

\section{TABLA 3}

Razones principales del aumento de la delincuencia y la inseguridad

\begin{tabular}{|c|c|c|c|}
\hline Razones 1.er lugar & $\begin{array}{c}\% \\
\text { Total }\end{array}$ & Razones $20^{\circ}$ lugar & $\%$ \\
\hline $\begin{array}{l}\text { Paro en general } \\
\text { Incremento consumo drogas } \\
\text { Situación económica } \\
\text { Poca dureza penas } \\
\text { Falta de educación } \\
\text { Estructura social injusta } \\
\text { Pérdida valores morales } \\
\text { Influencia TV/cine } \\
\text { Excesiva tolerancia social } \\
\text { Falta preocupación } \\
\text { Ineficacia política } \\
\text { N/S, N/C } \\
\text { Otras }\end{array}$ & $\begin{array}{r}35,5 \\
27,3 \\
8,9 \\
8,8 \\
5,2 \\
4,2 \\
3,3 \\
2,5 \\
2,0 \\
0,9 \\
0,7 \\
0,4 \\
0,3\end{array}$ & $\begin{array}{l}\text { Incremento consumo drogas } \\
\text { Paro en general } \\
\text { Situación económica } \\
\text { Poca dureza penas } \\
\text { Falta de educación } \\
\text { Pérdida valores morales } \\
\text { Estructura social injusta } \\
\text { Influencia TV/cine } \\
\text { Excesiva toletancia social } \\
\text { Falta preocupación } \\
\text { Ineficacia política } \\
\text { N/S, N/C } \\
\text { Otras }\end{array}$ & $\begin{array}{r}24,2 \\
20,4 \\
17,9 \\
10,0 \\
8,6 \\
4,8 \\
4,4 \\
2,5 \\
2,3 \\
2,1 \\
1,6 \\
0,7 \\
0,4\end{array}$ \\
\hline Razones 3. er lugar & $\begin{array}{c}\% \\
\text { Total }\end{array}$ & $\begin{array}{l}1 .^{e r}+20^{\circ}+3 .^{\text {er }} \\
\text { Razones total }\end{array}$ & $\begin{array}{c}\% \\
\text { Total }\end{array}$ \\
\hline $\begin{array}{l}\text { Incremento consumo drogas } \\
\text { Situación económica } \\
\text { Paro en general } \\
\text { Falta de educación } \\
\text { Poca dureza penas } \\
\text { Pérdida valores morales } \\
\text { Estructura social injusta } \\
\text { Falta preocupación } \\
\text { Excesiva tolerancia social } \\
\text { Influencia TV/cine } \\
\text { Ineficacia política } \\
\text { Otras } \\
\text { N/S, N/C }\end{array}$ & $\begin{array}{r}16,0 \\
14,8 \\
14,1 \\
12,3 \\
11,9 \\
6,3 \\
6,0 \\
4,3 \\
4,1 \\
3,9 \\
3,4 \\
1,3 \\
1,3\end{array}$ & $\begin{array}{l}\text { Paro en general } \\
\text { Incremento consumo drogas } \\
\text { Situación económica } \\
\text { Poca dureza penas } \\
\text { Falta de educación } \\
\text { Estructura social injusta } \\
\text { Pérdida valores morales } \\
\text { Influencia TV/cine } \\
\text { Excesiva tolerancia social } \\
\text { Falta preocupación } \\
\text { Ineficacia política } \\
\text { Otras } \\
\mathrm{N} / \mathrm{S}, \mathrm{N} / \mathrm{C}\end{array}$ & $\begin{array}{r}70,0 \\
67,5 \\
41,6 \\
30,8 \\
26,1 \\
14,6 \\
14,4 \\
8,9 \\
8,5 \\
7,3 \\
5,8 \\
1,9 \\
0,4\end{array}$ \\
\hline
\end{tabular}


TABLA 4

Medidas que habría de tomar la Administración (espontáneas/sugetidas)

\begin{tabular}{|c|c|c|c|}
\hline Medidas (espontáneas) & $\begin{array}{c}\% \\
\text { Total }\end{array}$ & Medidas (sugeridas) & $\begin{array}{c}\% \\
\text { Total }\end{array}$ \\
\hline $\mathrm{N} / \mathrm{S}, \mathrm{N} / \mathrm{C}$ & $21,0-0,4$ & Solucionar problema paro & 40,2 \\
\hline Solucionar problema paro & 18,5 & Más control de drogas & 25,9 \\
\hline Sancionar con mayor rigor & 15,6 & Potenciar guardias de barrio & 20,1 \\
\hline Más control de las drogas & 15,2 & Más educación & 16,8 \\
\hline Más educación & 15,0 & Sancionar con mayor rigor & 15,5 \\
\hline Incrementar policías & 7,9 & Centros de juventud & 14,1 \\
\hline Control de juventud & 6,7 & Penas más severas & 13,3 \\
\hline Potenciar guardias de barrio & 6,0 & Incrementar vigilancia nocturna & 9,9 \\
\hline Otras respuestas & 5,7 & Reformas sociales & 9,4 \\
\hline Reformas sociales & 4,7 & Potenciar policía autónoma & 7,6 \\
\hline Elevar nivel profesional & 3,0 & Más orden/autotidad & 7,2 \\
\hline Más orden/autoridad & 3,0 & Incrementar policías & 6,3 \\
\hline Incrementar vigilancia nocturna & 2,5 & Elevar nivel profesional & 5,5 \\
\hline Escolarización & 2,2 & Centros de infancia públicos & 2,6 \\
\hline Penas más severas & 2,1 & Centros asistenciales & 2,5 \\
\hline Nuevas leyes & 1,8 & $N / S$ & 0,7 \\
\hline Concienciación de convivencia & 1,8 & & \\
\hline Valores morales & 1,4 & & \\
\hline Más eficacia policial & 1,3 & & \\
\hline Potenciar policía autónoma & 1,3 & & \\
\hline Centros de rehabilitación & 1,2 & & \\
\hline Reinserción social & 1,1 & & \\
\hline Centros de infancia públicos & 1,0 & & \\
\hline Agilización de la Adm. justicia & 0,9 & & \\
\hline Colaboración vecinos/policía & 0,8 & & \\
\hline Centros asistenciales & 0,8 & & \\
\hline Pena de muerte & 0,7 & & \\
\hline Reforma del sistema penal & 0,6 & & \\
\hline Control droges & 0,6 & & \\
\hline Eliminar imágenes violencia & 0,4 & & \\
\hline Mejor calidad de vida & 0,3 & & \\
\hline Entendimiento policía/jueces & 0,2 & & \\
\hline Reestructuración policial & 0,2 & & \\
\hline Medicina preventiva & 0,1 & & \\
\hline Ninguna & 0,1 & & \\
\hline
\end{tabular}

11. 
«Papers»: Revista de Sociologia

\section{TABLA 5}

Actitudes ante las leyes y jueces (\% total)

\begin{tabular}{|c|c|c|c|}
\hline Actitudes & Acuerdo & $\begin{array}{l}\text { Desa- } \\
\text { cuerdo }\end{array}$ & $N / S N / C$ \\
\hline $\begin{array}{l}\text { La Ley es igual para todos ...................... } \\
\text { Si las leyes fuesen más duras habría menos de- }\end{array}$ & 31,4 & 65,0 & 3,6 \\
\hline $\begin{array}{l}\text { lincuentes } \ldots \ldots \ldots \ldots \ldots \ldots \ldots \ldots \ldots \ldots \ldots \ldots \ldots \ldots \ldots \ldots \ldots \ldots \\
\text { Los delitos de sangte tendrían que castigarse }\end{array}$ & 68,3 & 27,1 & 4,7 \\
\hline 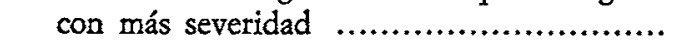 & 84,7 & 10,8 & 4,4 \\
\hline Hoy en día casi compensa cometer un robo ... & 39,1 & 52,7 & 8,2 \\
\hline Los juzgados y los jueces están desbordados ... & 78,8 & 8,7 & 12,6 \\
\hline $\begin{array}{l}\text { Lentitud y pesadez de la justicia española ....... } \\
\text { Sería conveniente un mejor entendimiento poli-. }\end{array}$ & 90,7 & 2,3 & 7,0 \\
\hline El fiscal del distrito debería garantizar seguri- & 82,2 & 3,5 & 14,3 \\
\hline 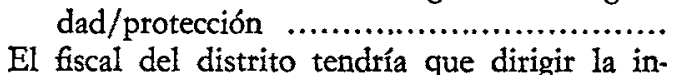 & 64,6 & 6,8 & 28,6 \\
\hline $\begin{array}{l}\text { vestigación policial .............................. } \\
\text { Los jueces deberían actuar con más rigor/du- }\end{array}$ & 60,4 & 7,5 & 32,1 \\
\hline 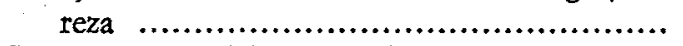 & 73,7 & 14,7 & 11,6 \\
\hline $\begin{array}{l}\text { La gente no colabora con la justicia ............ } \\
\text { Si existiera el jurado se aplicaría mejor la jus- }\end{array}$ & 89,8 & 6,2 & 4,1 \\
\hline 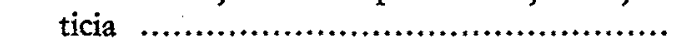 & 61,6 & 14,6 & 23,8 \\
\hline $\begin{array}{l}\text { La práctica del soborno no es infrecuente ...... } \\
\text { La gente ha perdido confianza en la justicia es- }\end{array}$ & 53,4 & 18,3 & 28,3 \\
\hline 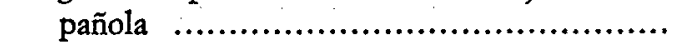 & 81,2 & 12,3 & 6,5 \\
\hline
\end{tabular}


Desviación y control en las sociedades avanzadas

\section{BIBLIOGRAFIA}

Bonnemaison, Face à la dêlinquence: prévention, répression, solidarité, rapport au Premier Ministre, La Documentation Française, París 1982.

Coing, H. y Meunier, Ch., Insecurité Urbaine?, Ed. Anthropos, París 1980.

Comissió Tècnica de Seguretat Urbana, «Informe del Grup de Treball d'Anàlisi», Ajuntament de Barcelona 1985.

Comissió Tècnica de Seguretat Urbana, «Propostes d'actuació sobre Seguretat a Barcelona», Ajuntament de Barcelona 1985, a.

Dirección General de Policía, «La delincuencia común en 1984», D. G. de la Policía, Madrid 1985.

Dulong, R., Com la inseguretat desafia el sociòleg, en «Papers», revista de Sociologia 24 (1985), pp. 145-157.

- y otros, Imaginaires de l'insécurité, Librairie des Meridiens, París 1983.

García-Barbancho, A., Población, empleo y paro, Ed. Pirámide, Madrid 1982.

Merton, R., Teoría y estructura sociales, FCE, México 1964.

Peyrefitte, A., Réponses a la violence, Presses Pocket, París 1977.

Pinatel, J., Traité de Droit Pénal et de criminologie, Dalloz, París 1971.

- La sociedad criminógena, Aguilar, Madrid 1979.

Rizzi, B., La burocratización del mundo, Ediciones Península, Barcelona 1980.

Robert, Ph., Insécurité, opinion publique et politique criminelle, en «L'année Sociologique» 35 (1985), pp. 199-231. 